\title{
Research for Health Equity: Knowing is Not Enough
}

In 1990, a seminal report from the Commission on Health Research for Development pointed to the gross imbalance between the magnitude of diseases affecting the world's poor majority and the meager funds spent on research to fight them. Responding to growing momentum, in 1997 the Global Forum for Health Research was founded to address this skewed research agenda. Fast-forwarding to 2009, the Geneva-based organization held its $13^{\text {th }}$ meeting in Havana on the theme Innovating for the Health of All, inspiring collaboration between MEDICC Review and Forum organizers for an issue dedicated to research, innovation and global health equity.

The history of the Global Forum reflects the sometimes tortuous evolution of global thinking on the role of research in solving the big health problems of a world in which the disparities between rich and poor countries have grown wider, and the health-related Millennium Development Goals are the least likely to be met (Forum 2009: Innovating for the Health of All). If the crux of the problem in 1997 was lack of financing for biomedical research on diseases of the poor, over time the health equity lens has revealed other, more complex dimensions of the factors influencing research priorities and the eventual application of their findings.

We now know, through often unfortunate trial-and-error, that even when biomedical R\&D has the right focus and funding-yielding a discovery, invention or product-this is not enough to make the leap to effective application. It took 264 years after the discovery that lemon juice prevented scurvy for the British Navy to supply citrus fruit on its ships. Equipped with exponentially better science to confront infinitely greater problems, we are challenged to do better. Yet, as noted in the 2004 World Report on Knowledge for Better Health: "The failure to use effective interventions is a global problem." Precisely this dilemma motivated Forum 2009 organizers to focus on innovation as a multi-faceted process from knowledge generation, through application and finally transformation of population health outcomes. Such an approach moved the debates from the comfort zone of biomedical and technological research to introduce tough questions about implementation, bringing in discussion of health systems, social innovation, and ways for equity-guided research to become more influential in policy decisions.

In this context, MEDICC Review highlights the contributions of Cuba and other developing nations to the evidence suggesting that only through simultaneous development of technologies and public health strategies can disease be effectively tackled and prevented (Three-Pronged Innovation to Improve Care for Acute Myocardial Infarction Patients in Cuba and Effectiveness and Safety of ior ${ }^{\circledR}$ EPOCIM for Chemotherapy- or Radiotherapy-Induced Anemia in Pediatric Cancer Patients). In turn, this requires the political will to consciously develop health research capacities and a health research system with lines of investigation well-matched to disease burden and national public health priorities (Limited Financial Resources Need Not Mean Poor Health Outcomes).

Although no developing country has reached the goal of devoting $2 \%$ of its health budget to research for health endorsed by the
2008 Global Ministerial Forum on Research for Health, Cuba is one of only three countries in Latin America spending over 1\%. Cuba has trained a formidable cadre of researchers, including practicing health professionals. Moreover, the Ministry of Public Health systematically formulates research priorities based on burden of disease, and facilitates Cuban researchers' participation in multinational studies such as those conducted by the 10/66 Dementia Research Group (Prevalence of Stroke and Associated Risk Factors in Older Adults in Havana City and Matanzas Provinces, Cuba). However, it was not until 2009 that the Ministry turned a traditionally top-down methodology on its head to begin national research priority-setting by consulting health care providers and others at the municipal level (Shaping a Research Agenda to Solve Health Problems), revealing knowledge gaps and important variations in local health issues.

\section{....away from the comfort zone of biomedical and technological research...}

Brazil, the fastest-growing economy in Latin America, is also a driver of research for public health application in the region and the global South. A joint endeavor with Cuba illustrates the potential of South-South collaboration to generate innovative solutions to pressing health problems, implement technology transfer and harmonize regulatory processes. This cooperation also resulted in life-saving assistance in response to a health crisis in several African nations (Cuba and Brazil: An Important Example of South-South Collaboration in Health Biotechnology). The theme of South-South cooperation is further explored in our continuing coverage of Cuban-Haitian recovery efforts after the January earthquake (Mental Health Services in Post-Quake Haiti).

Finally, two articles explore difficult challenges facing a global research agenda that promotes the right to health and studies the root causes of ill-health and related inequities. The first, Innovations for Global Health Equity: Beyond Open Access towards Open Data, addresses the global health information gap, and argues for resources and policies favoring improved collection, availability and transparency of health data. The second, Overcoming Barriers to Improved Research on the Social Determinants of Health, cautions that changes are needed in the way public health research is funded, assessed, rewarded and published if it is to contribute to improved action on social determinants of health.

Over the last year preparing this issue, we have been exceptionally fortunate to count on the wisdom and expertise of two guest editors: Susan Jupp, external relations director for the Forum through its 2009 meeting; and María Guadalupe Guzmán of the Forum's governing Foundation Council and the Pedro Kourí Institute of Tropical Medicine in Havana. We are also grateful for support received for the issue from The Atlantic Philanthropies and The Rockefeller Foundation.

\section{The Editors}

